\title{
Malformación pulmonar quística insuflada
}

\author{
Drs. Francisco Ossandón Correa* y Galicia Montecinos Latorre.*
}

\section{INTRODUCCION}

Las malformaciones pulmonares son mucho menos frecuentes que las cardiovasculares, renales y del tubo digestivo. Quizás por ello los Cirujanos infantiles no estamos habituados a su manejo rutinario y la aparición de casos siempre despierta gran interés. En los últimos años hay series grandes como la de Szöts de Budapest, 215 $\operatorname{casos}^{(1)}$, que contrastan con los 20 casos de Ravitch en $1966^{(2)}$. En los dos últimos años, hemos tenido, en el Hospital Regional de Temuco, cinco malformaciones pulmonares en niños: dos Agenesias unilaterales, una Agenesia de lóbulo inferior izquierdo y dos malformaciones quísticas, siendo estas últimas el motivo de esta presentacion. En la literatura nacional encontramos el trabajo del Dr. E. Cortés, del Hospital M. Arriarán, con cuatro casos de Quiste Bronquial Congénito $^{(3)}$. Nuestros dos casos clínicos presentaron malformación quística unlateral hiperinsuflada, lo que obligó a intervención de urgencia por su gravedad.

Hemos querido titular así este trabajo, sin comprometernos en el diagnóstico histopatológico, que desgraciadamente no pudimos tener.

\section{MATERIAL CLINICO}

CASO N-1:

L.M.A., hombre, ingresa al mes veinticinco días de edad, con antecedentes de "cansancio para respirar y quejido" desde el nacimiento. El cuadro se agravó en los últimos cuatro días con tos coqueluchoidea y cianosis. Antecedentes de influenza en el embarazo, parto espontáneo en el Hospital de Cunco, peso de nacimiento $2.500 \mathrm{gr}$.

En el examen llamó la atención gran disnea, retracción intercostal, accesos de tos coqueluchoidea con cianosis. En campo pulmonar izquierdo se auscultaron gran cantidad de

*Servicio de Cirugia Infantil y Ortupedia, Hospital Regional de Temuco. crépitos y respiración soplante. Se catalogó como Neumopatía aguda izquierda e ingresó a Pediatría. Su evolución fue tórpida y después de veinte dias de hospitalización se decidió hacer estudio radiológico de Tórax y Esófago-Estómago-Duodeno para descartar reflujo gastroesofágico. No se realizaron exámenes y por una epidemia de Salmonellosis intrahospitalaria el enfermo se fue de alta a su casa después de un mes y medio de hospitalización. Reingresó a los veinte días del alta, grave, por reinstalación del cuadro agudo respiratorio, que se catalogó como de probable origen estafiloć́cico y se practicó radiografa de Tórax que reveló hiperinsuflación del pulmón derecho, con hernia mediastínica de él a izquierda, imágenes bulosas en campo derecho y desviación de mediastino a izquierda (Fig. 1).

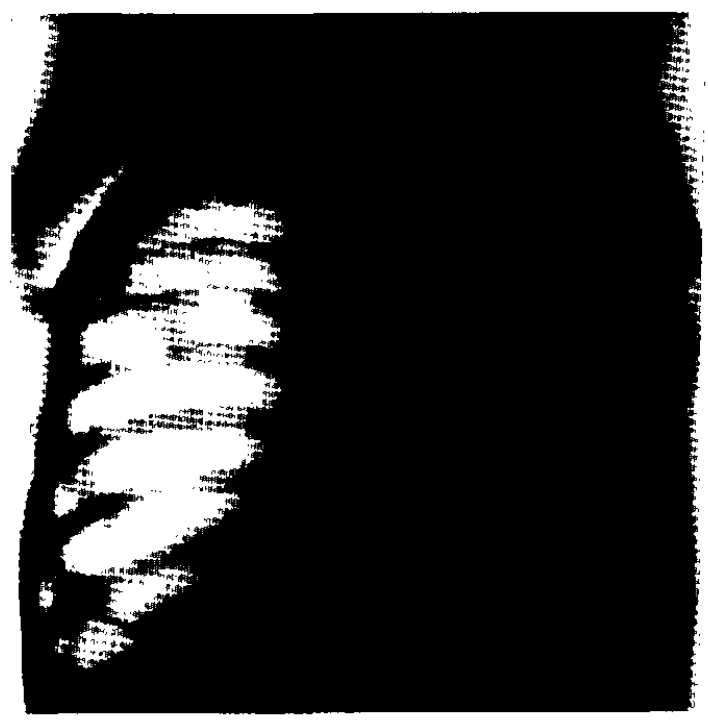

A los diez días del reingreso se pidió interconsulta a Cirujanos Infantiles, apreciando al examen un enfermo grave, cianótico con distress importante, retracción costal, polipnea y en la radiografía de Tórax se confirmó lo anteriormente descrito. Se intervino de urgencia el mismo día, produciéndose paro cardiorrespinatorio en la inducción anestésica. Se practicó entonces toracotomía derecha en quinto espacio intercostal en forma ultrarrápida, logrando luxar el pulmón quístico por herida operatoria, descomprimiendo mediastino y recuperando al enfermo por masaje cardiaco y ventilación con oxígeno puro. Una vez restablecida la normalidad circulatoria, se observó que el segmento quístico hiperinsuflado correspondía a un proceso localizado en el segmento basal anterior del lobulo inferior 
derecho, el cual se encontraba parcialmente separado del parénquima pulmonar sano (Fig. 2). Todo el resto del pulmón derecho era normal y se encontraba atelectasiado por compresión. Se ligaron en forma independiente los vasos pulmonares segmentarios y el bronquio correspondiente, extirpando el segmento enfermo en block, y se obtuvo así una buena expansión pulmonar derecha.

\section{CASO-1}

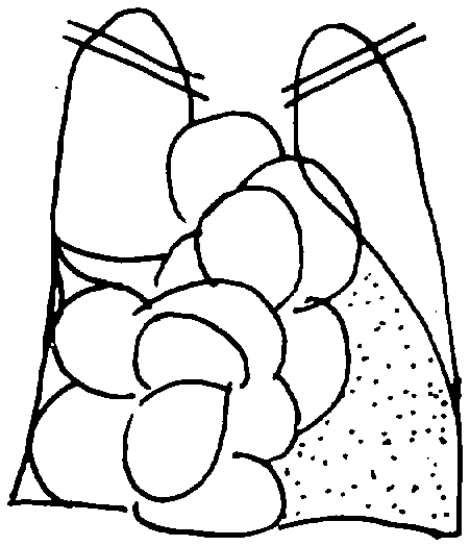

\section{Segmento Basal Anterior}

\section{LOBULO INFERIOR DERECHO.}

La evolución post-operatoria fue sin contratiempos, retirando sondas pleurales al tercer día y los puntos al décimo. Alta a los veinte días de operado. El control hasta el año de postoperado muestra un lactante que progresa bien con una curva ponderal recuperada, anemia hipocroma moderada y sin cuadros respiratorios de importancia. En la radiografía de Tórax, discreta paquipleuritis.

\section{CASO N-2:}

P.K.P., hombre, de cinco meses de edad, que ingresó en grave eśtado enviado desde consultorio médico. Antecedentes de un cuadro respiratorio de evolución progresiva que se trató ambulatoriamente con diversos broncodilatadores y antibioticos. En control radioscópico el médico tratante descubrió lo que le parecía un neumotorax espontáneo en un enfermo cianótico, pálido y con gran distress respiratorio. El corazón latia a derecha. Se practicó radiografia de Tórax urgente, apreciando gran bula hiperinsuflada que ocupaba hemicampo izquierdo, desviando mediastino a derecha y comprimiendo pulmón derecho (Fig. 3).

Se practicó pleurotomía en segundo espacio intercostal izquierdo y línea medio clavicular, obteniendo escaso aire de cavidad pleural. Se intervino quirúrgicamente a las cuatro horas de su ingreso, practicando toracotomía en quinto espacio intercostal izquierdo. Al abrir pleura se apreció gran quiste hiperinsuflado en segmento posterior del lobulo superior izquierdo (Fig. 4). Se abrió el quiste escapando aire, sin existir mucus en su interior y se resecó toda la capa pleural del quiste. Hacia el Hilio se apreciaron quistes satélites que se fueron destechando hasta obtener una sola gran cavidad. Se suturaron

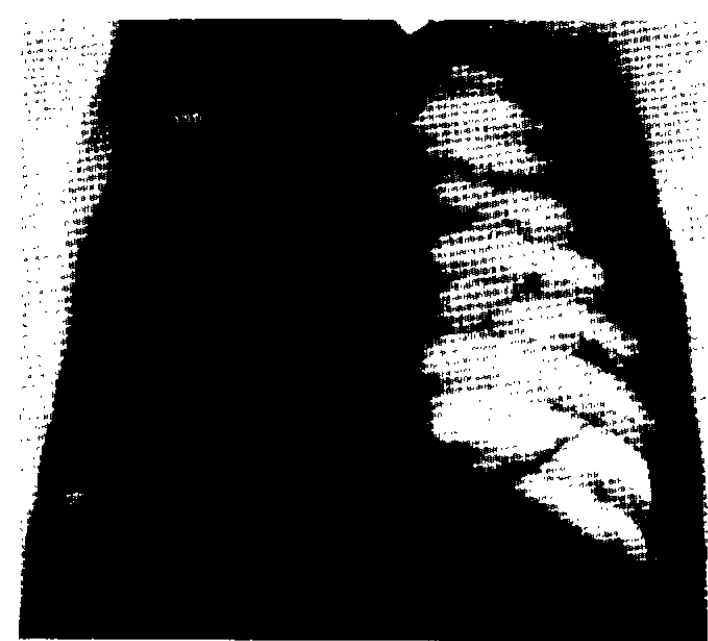

\section{CASO - 2}

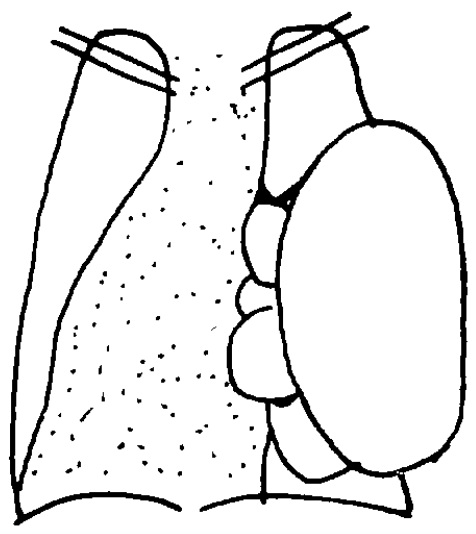

Segmento Posterior

\section{Lobulo Supertor Izquierdo.}

bronquios comunicantes a la cavidad quística y se practicó un surjet de Catgut cromado en el borde lateral de la cavidad según la técnica de Allende-Langer. Con ello se logró un cierre hermético de todas las comunicaciones bronquiales. Prácticamente todo el parénquima enfermo fue extirpado y se obtuvo buena expansión del lóbulo superior y lóbulo inferior que se encontraba atelectasiado por compresión.

La evolución post-operatoria no tuvo incidentes, se retiraron sondas pleurales al quinto día de post-operado, observando en la radiografía de control una buena expansión pulmonar, mediastino centrado y un área de infiltración pulmonar moderada en la zona operatoria. Alta a los doce días de operado, habiendo retirado los puntos al décimo día. Los controles ambulatorios hasta nueve meses de operado muestran un lactante que progresa bien, sin problemas de tipo respiratorio $y$ con un leve velamiento residual en tercio medio externo del hemicampo izquierdo, en correspondencia con la zona operatoria. 


\section{COMENTARIO}

Tradicionalmente se plantea que el tratamiento quirúrgico de los quistes pulmonares congénitos es la resección del quiste, el segmento o el lóbulo pulmonar enfermo, como lo fuera en el primer caso. Sin embargo en nuestro segundo caso, dado que los múltiples quistes comunicaban entre sí y que a pesar de su gran tamaño afectaban una pequeña porción del lóbulo pulmonar, pensamos que comunicando todas estas cavidades entre sí, resecando sus tabiques para convertirlo en un solo gran quiste, el que posteriormente se trató según la técnica de Allende-Langer, obtendríamos un buen resultado. La evolución del enfermo así lo ha demostrado, llegándose a la normalidad clínica y radiológica en los ya ocho meses de postoperatorio. Tal vez un inconveniente que pudiera presentarse con esta técnica es que la presencia de glándulas mucosas en las paredes del quiste residual, que queda abierto a cavidad pleural, pudiera ocasionar una colección de mucus pleural difuso o enquistado. No ocurrió así en este caso, pero debemos recalcar que los quistes sólo contenían aire y no mucus.

En el primer caso presentado pudiera postularse que se trataba de un lóbulo secuestrado. Ello se descarta sin embargo, pues por definición estas malformaciones tienen irrigación directa de la aorta, lo que no observamos en nuestro enfermo. Pudiera tratarse eso sí de un lóbulo izquierdo supernumerario, y no de un segmento del lóbulo inferior, ya que su conexión parenquimatosa con este último era escasa y no así el bronquio fuente que nacía del bronquio del lóbulo inferior izquierdo. No hubo complicaciones en el postoperatorio y como la resección fue de todo el parénquima enfermo, no son de esperar en el futuro.

Es interesante recalcar que ambos enfermos debieron ser intervenidos de urgencia, a pesar de la larga hospitalización del primer caso, en que diversos factores retardaron el diagnóstico. Fue determinante la toracotomía rápida, con el fin de descomprimir mediastino y pulmón sano, para obtener un alivio de los enfermos en riesgo de muerte, aun encontrándose intubados y con ventilación asistida.

\section{RESUMEN}

Se presentan dos casos clinicos de Malformación Pulmonar Quística Hiperinsuflada, de caracter segmentario unilateral, con grave desviación de mediastino y compromiso vital. Ambos operados con éxito, practicando resección del segmento quístico en un caso y quistectomía según la técnica de AllendeLanger en el otro. Se comentan las técnicas empleadas, recalcando el buen resultado post-operatorio obtenido.

\section{SUMMARY}

We present two cases of unilateral hiperinsuflated pulmonary cysts, which involved a localized segment of the lung, and provoked respinatory insufficiency with mediastinal deviation. Both operated with success, using a pulmonary segmentectomy iI one case and a partial cystectomy according to the AllendeLanger technic in the other. We conment the surgical technic employed reassuring the good post operative result.

\section{REFERENCIAS}

1 Szöts I, Tóth T. Progress in Ped. Surg. Vol. 10 p. 277; 1977.

2 Benson, Mustard y otros. Cinggía Infantil. Tomo I p. 394; 1966.

3 Cortés E., y col. Rev. Chil. Ped. Vol. 46 N-3, 1975. 